mentosa, ${ }^{6}$ chronic ischaemic branch retinal vein obstruction, ${ }^{7}$ and retinopathy of prematurity, ${ }^{8}$ as well as systemic diseases including muscular dystrophy, Senior-Loken syndrome (renal retinal dystrophy), and Turner's syndrome. ${ }^{9}$ To our knowledge, this is the first report of a Coats'-like response in pars planitis.

The aetiology of retinal telangiectasis, either congenital or secondary, remains unclear. Histopathological specimens show functional or structural loss of the blood-retinal barrier, and disorganisation of mural architecture. ${ }^{10}$ Reese $^{4}$ conjectured that endothelial cell dysfunction causes localised microvascular atresia and occlusion, which leads to vascular ectasia and collateral vessels. A vaso-occlusive event may precede the development of retinal telangiectasis. ${ }^{7}$ In Coats'-type retinitis pigmentosa, additional possible aetiologies include autoimmune vasculopathy, and chronic subretinal uveitis from subretinal leakage of inflammatory and immunogenic serum constituents. ${ }^{8}$ The Coats'-like response in our patient occurred in the eye that had historically been more severely affected by pars planitis; progression of the Coats'-like response suggests ongoing damage to the retinal vasculature secondary to the chronic inflammation of pars planitis.

PHILIP P CHEN

LAWRENCE P CHONG Doheny Eye Institute, University of Southern California School of Medicine, 1450 San Pablo Street, Los Angeles, CA 90033, USA

Correspondence to: $\mathrm{Dr}$ Chen

Accepted for publication 11 March 1996

1 Dugel PU, Smith RE. Pars planitis. In: Ryan SJ, ed. Retina. 2nd ed. St Louis: Mosby, 1995:1621-31.

2 Felder KS, Brockhurst RJ. Neovascular fundus abnormalities in peripheral uveitis. Arch Ophthalmol 1982;100:750-4.

3 Kalina PH, Pach TM, Buettner H, Robertson DM. Neovascularization of the disc in pars planitis. Retina 1990;10:269-73.

4 Reese AB. Telangiectasis of the retina and Coats' disease. Am $\mathcal{F}$ Ophthalmol 1956;42:1-8.

5 Fox KR. Coats' disease. Metab Pediatr Ophthalmol 1980;4:121-4.

6 Khan JA, Ide $\mathrm{CH}$, Strickland MP. Coats's-type retinitis pigmentosa. Surv Ophthalmol 1988;32: 317-32.

7 Scimeca G, Magargal LE, Augsburger JJ. Chronic exudative ischemic superior temporal-branch retinal vein obstruction simulating Coats's disease. Ann Ophthalmol 1986;18:118-20.

8 Tasman WS. Exudative retinal detachment in retrolental fibroplasia. Trans Am Acad Ophthalmol Otolaryngol 1976;81:535.

9 McDonald HR, Schatz H, Johnson RN, Madeira $D$. Acquired macular disease. In: Tasman W/ ed. D. Acquired macular disease. In: Tasman W, ed. Duane's clinical ophthalmology. Philadelphia: Lip-
pincott, 1990. pincott, 1990

Tarkkanen A, Laatikainen L. Coats's disease: clinical, angiographic, histopathological findings and clinical management. Br F Ophthalmol $1983 ; 67: 766-76$.

\section{Management of a patient with pseudophakic malignant glaucoma; role of ultrasound biomicroscopy}

EDITOR,-Malignant glaucoma is characterised by increased intraocular pressure (IOP) accompanied by shallowing or flattening of the anterior chamber, despite treatment with patent iridectomy and the presence of a normal posterior segment. ${ }^{1}$ We describe a patient with pseudophakic malignant glaucoma, a serious disorder, who was treated successfully with pars plana vitrectomy. High frequency ultrasound biomicroscopy, a new technique for examining the ocular tissue even

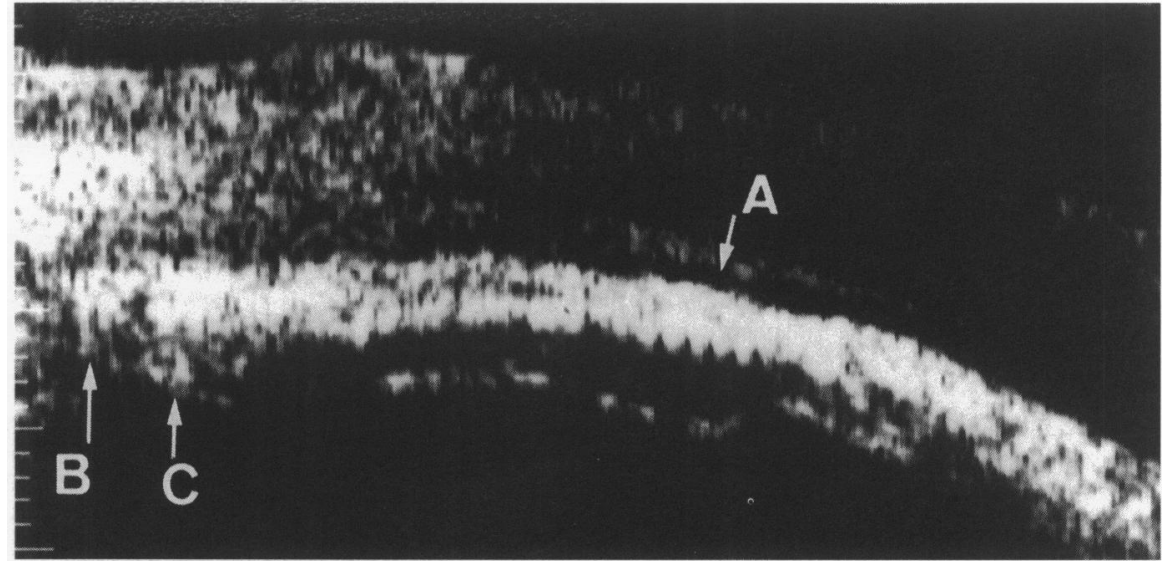

Figure 1 Ultrasound biomicroscopy before Nd-YAG hyaloidectomy. From the temporal angle, the anterior chamber $(A)$ is slit-like with peripheral iridocorneal apposition. The zonular-capsular inflammatory barrier (B), including a shadow, suspected to be haptic of IOL (C), is attached behind the iris.

behind the iris in vivo, ${ }^{2}$ clarified the mechanism of ciliovitreal block and the misdirection of aqueous flow following cataract surgery and implantation of a posterior chamber lens. ${ }^{3}$

\section{CASE REPORT}

A 65-year-old Japanese woman with a history of bilateral primary angle closure glaucoma had undergone successful bilateral argon laser iridotomies by a local physician in mid May 1994. However, she experienced a gradual increase in IOP in the left eye and shallowing of the anterior chamber in early March 1995. Despite medication, an increase in peripheral anterior synechia (PAS) was observed in the left eye, and the IOP remained elevated $(>21$

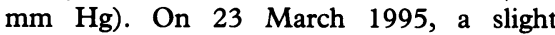
posterior subcapsular cataract was removed by planned extracapsular extraction, with implantation of a posterior chamber intraocular lens (three piece IOL, optic diameter 6.5 $\mathrm{mm}$ ) into the capsular bag, and a periphera iridectomy performed at the 12 o'clock position. About 20 days postoperatively, the depth of the anterior chamber in the left eye gradually decreased, and the IOP again rose. A second peripheral iridectomy was performed at the 2 o'clock position on 3 April, but the IOP remained high despite full medication.

The patient was then referred to our department on 8 June 1995. The anterior chamber was slit-like and the IOP in the left eye was $33 \mathrm{~mm} \mathrm{Hg}$ with marked corneal

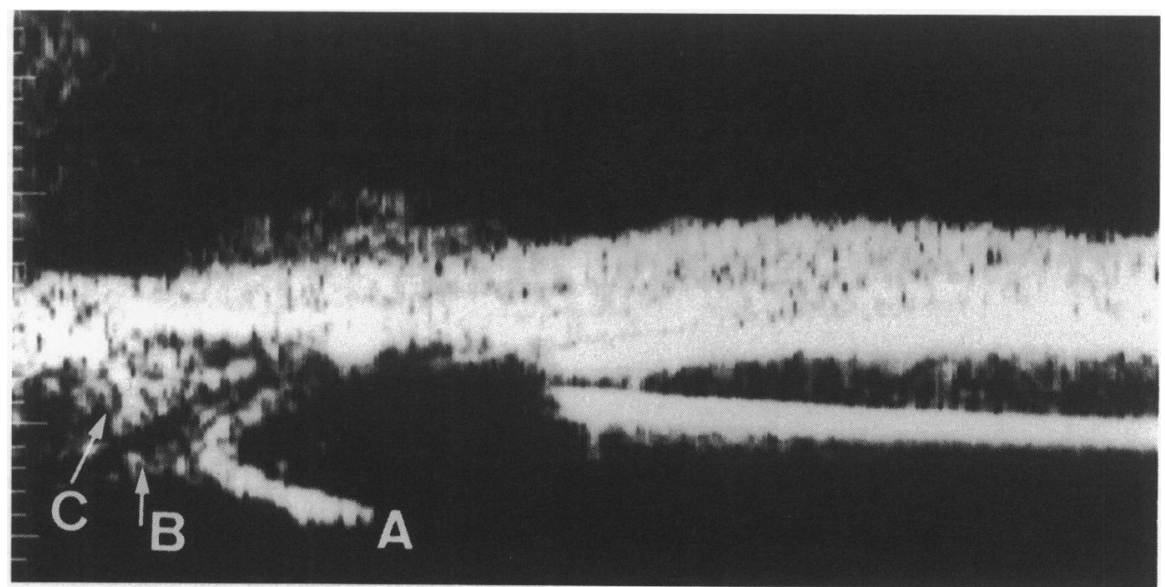

Figure 2 Ultrasound biomicroscopy after Nd-YAG hyaloidectomy. The anterior chamber was deepened after performance of the Nd-YAG laser. In the temporal angle, the peripheral portion of the haptic $(A)$ of the posterior chamber lens is still attached to the cilio-zonular barrier (B). Anterior rotation of the ciliary body $(C)$ is observed near the haptic. oedema. Despite the flatness of the anterior chamber with the patency of iridectomy, there were no signs of forward bowing of the iris, choroidal haemorrhage, or choroidal effusion in either eye. Ultrasound biomicroscopy (UBM-840, Humphrey Instruments Inc, USA) revealed a marked forward displacement of the lens haptic and a dense zonular capsular barrier, with the apposition to the iris root (Fig 1)

Nd-YAG hyaloidectomy was performed on 8 June 1995. Photodisruption of the anterior hyaloid surface immediately deepened the anterior chamber and created a pathway for the anterior flow of aqueous humour. However, such laser treatment did not reverse the glaucoma, because of the broad peripheral anterior synechiae (PAS) due to long standing peripheral iridocorneal apposition. Ultrasound biomicroscopy showed that, despite deepening of the anterior chamber, the anatomical relative positions around the ciliary body were unchanged, and the apposition of the lens haptic to the zonular capsular barrier persisted (Fig 2). Two days later, trabeculectomy was performed on the temporal lower quadrant after application of mitomycin C. On the first postoperative day after trabeculectomy, a massive amount of fibrin and severe hyphaema were detected in the anterior chamber, and IOP was $53 \mathrm{~mm} \mathrm{Hg}$ without a filtering bleb. Two days later, a pars plana vitrectomy was performed through the scleral flap created by the last trabeculectomy. Anterior cortical vitrectomy, which involved 
excision of a localised area of posterior lens capsule and zonules with washing of hyphaema out of the anterior chamber, was performed to prevent closure of the keyhole created by the Nd-YAG laser. Pars plana vitrectomy reversed the glaucoma process with a filtering bleb. The patient's condition remains stable 5 months after the procedure.

\section{COMMENT}

From the interpretation of clinical course, it is clear that this patient suffered from chronic narrow angle/mixed type of glaucoma and that surgical trabeculectomy, rather than peripheral iridectomy, would have been the correct adjunct procedure at the time of cataract extraction.

Several reports have cited a misdirection of aqueous flow due to ciliary block as the mechanism of malignant glaucoma, even in patients with a normal posterior chamber lens. ${ }^{3-5}$ Following the extracapsular IOL implantation, the eye may contain residual and fibrocellular materials in addition to a posterior capsule and lens zonules. These materials, as well as surgical manipulation, may cause inflammation around the ciliary body and in the anterior vitreous postoperatively. This zonular-capsular inflammatory barrier ${ }^{5}$ and the postoperative swelling of the ciliary body may contribute to the blockage of the aqueous flow from the posterior segment to the anterior chamber. The misdirection of aqueous flow may accelerate, leading to the forward displacement and compression of the anterior vitreous which, in turn, leads to adhe sion between the vitreous body and the zonular-capsular inflammatory barrier.

Viewing of the posterior chamber with the ultrasound biomicroscope allows for clarification of the underlying mechanism of misdirection of aqueous flow in glaucoma, and helps in selecting the therapy required for this type of glaucoma. The ultrasound biomicroscopic findings in our patient demonstrated anterior rotation of the ciliary body which suggested an abnormal ciliovitreal anatomical relation that caused a misdirection of the aqueous flow. The marked forward displacement of the posterior chamber IOL and the zonular-capsular inflammatory barrier, reflecting high pressure in the vitreous cavity, physically pushed the iris against the trabecular meshwork and cornea. After performance of Nd-YAG hyaloidectomy through the pupil, the blockage of aqueous flow from the posterior segment was eliminated, resulting in a virtually norma anterior chamber. However, the anatomical relative positions around the zonular-capsular inflammatory barrier and ciliary body remained unchanged, probably because of organic adhesion. The surgical course and ultrasound biomicroscopic findings of our patient support the hypothesis that organic blockage at the ciliary body and the anterior vitreous plays an important role in the development of mechanisms of malignant glaucoma.

Treatment of malignant glaucoma includes cycloplegic drugs, osmotic agents, lens removal, laser disruption of the anterior hyaloid surface, ${ }^{6}$ and vitrectomy. ${ }^{5}$ When medical therapies, such as the administration of cycloplegic and osmotic agents, are not effec tive Nd-YAG hyaloidectomy should be performed as soon as possible. Nd-YAG hyaloidectomy usually eliminates the blockage of aqueous flow to the anterior chamber. If Nd-YAG treatment is not successful, pars plana vitrectomy should be performed without delay to minimise the development of PAS and other permanent structural damage.

MASAMI PARK KUNIKO UNIGAME JUNICHI KIRYU TAKEHISA KONDO Kobe City General Hospital, Department of Ophthalmology, Kobe 650, fapan

Correspondence to: Takehisa Kondo, MD, Kobe City General Hospital, Department of Ophthalmology, 4-6, Minatojima-nakamachi, Chuo-ku, Kobe, 650, Japan.

Accepted for publication 7 March 1996

1 Weiss DI, Shaffer RN. Ciliary block (malignant) glaucoma. Trans Am Acad Ophthalmol Otolaryngol 1972;76:450-61.

2 Pavlin CJ, Sherar MD, Foster FS. Subsurface ultrasound microscopic imaging of the intact eye. Ophthalmology 1990;97:244-50.

3 Tello C, Chi T, Shepps G, Liebmann J, Ritch R. Ultrasound biomicroscopy in pseudophakic malignant glaucoma. Ophthalmology 1993;100: $1330-4$.

4 Duy TP, Wollensak J. Ciliary block (malignant) glaucoma following posterior chamber lens

5 Lynch MG, Brown RH, Michels RG, Pollack IP, Stark WJ. Surgical vitrectomy for pseudophakic Stark WJ. Surgical vitrectomy for pseudophakic malignant glaud

6 Epstein DL, Steinert RF, Puliafito CA Neodymium-YAG laser therapy to the anterior hyaloid in aphakic malignant (ciliovitreal block) glaucoma. Am $\mathcal{F}$ Ophthalmol 1984;98:137-43. 